\title{
Review of: "The Foundation for a Smoke-Free World after two years: can it be trusted?"
}

\author{
Norbert Hirschhorn
}

Jean-Francois Etter has done thorough research into the Foundation for a Smoke Free World: its funding by Philip Morris International (PMI), its lack of transparency, a breakdown of how grant funds have been expended to date, and the inexperience of it Board members in tobacco control. (Full disclosure: I was a colleague of and consultant to FSFW President, Dr. Derek Yach, both in his role at WHO, and subsequently, FSFW was established.)

The claim is made by FSFW staff, as reported by Professor Etter, that all that possibly can be done to remain independent of PMI is being done. Professor Etter remarks, "Whatever the FSFW does, the perception of insufficient independence may never go away, but there is a trade-off between the need for independence and the need for oversight and accountability. Who better than its sole source of income can hold the Foundation accountable?"

I find this last sentence is astonishing -- "Quis custodiet ipsos custodes", who watches the watchmen? The history of Philip Morris's twisting of science and recruitment of scientists to spread disinformation would make one wholly suspicious of the new effort that can't help but be in support of the company's drive to make, market and sell ENDS (electronic nicotine delivery systems), including IQOS, PMI's heated tobacco product, as harm-reduction devices for smokers. The premise is that ENDS can reduce the prevalence of smoking. Would they be as effective as proved public health measures (taxation, bans on advertising and smoking in public spaces, among others)? Yet to be shown.

In defense of FSFW Professor Etter argues that it is harrassment of staff, board members, grantees, ("ostracized, silenced, excluded, even harassed and bullied") that forces the Foundation into its defensive posture. I find this odd. There is much history of tobacco-industry support of research (tobacco-related or other) that makes distrust the default position. Even tobacco control activists who support ENDS as harm reduction have steered clear of FSFW.

There is much evidence that research results funded by an industry -- tobacco, pharmaceutical, chemical -- are skewed favorably to the industry, whether "independent" or not. Why should we expect it to be different here? Many of the Foundation's grantees may be drawn from a pool of researchers unable to support their work with funding from nonindustry sources. Professor Etter realizes this:

"The fear of being harassed and the willingness to accept tobacco-related money has inevitably an impact on the people who apply for grants and who agree to collaborate with the Foundation. This self-selection of applicants may have an adverse impact on the usefulness and trustworthiness of the research the Foundation supports. The FSFW clearly has difficulty attracting experienced researchers, it is quite possible that new ideas and innovations can come from people outside the field, but inexperienced grantees may have difficulty producing useful work and 
understanding the importance of independence from the tobacco industry."

In other words, the game was up from the start. 